International Journal of

Engineering Research and

Development

10.29137/umagd.736065

Cilt/Volume:13 Sayı/Issue:2 Haziran/June 2021

Araştırma Makalesi / Research Article

\title{
Uçak Çakışma Saptama ve Çözümleme Problemi için Karma Tam Sayılı Doğrusal Programlama Modeli Yaklaşımı
}

\section{A Mixed Integer Linear Programming Approach for Aircraft Conflict Detection and Resolution Problem}

\author{
Ramazan Kürşat Çeçen iD \\ Eskişehir Osmangazi Üniversitesi, Eskişehir Meslek Yüksek Okulu, Motorlu Araçlar ve Ulaştırma Teknolojileri Bölümü, 26110 Eskişehir, TÜRKIYYE
}

Başvuru/Received: 13/05/2020

Kabul / Accepted: 02/02/2021

Çevrimiçi Basım / Published Online: 04/02/2021

Son Versiyon/Final Version: 18/06/2021

\section{$\ddot{O} \mathbf{z}$}

Hava taşımacılığındaki talep artışı gerek hava sahalarında gerekse havaalanlarında ciddi trafik yoğunluğuna neden olmaktadır. Bu yoğunluk hem gecikmelere hem de uçaklar arasında çakışmalara neden olabilmektedir. Bu çalışmada, uçaklar arasında oluşacak çakışmaların önlenmesi amacıyla uçak çakışma saptama ve çözümleme konusu ele alınmış ve problemin çözümü için karma tam sayılı doğrusal programlama modeli önerilmiştir. Önerilen matematiksel modelin test edilmesi için bir referans durum üretilmiştir. Bu referans durum hava sahasında ilk gelen ilk hizmet alır prensibi ile çakışmaların çözümlenmesini sağlamaktadır. Önerilen model ile toplam gecikme süresi ve gecikmeden kaynaklı toplam yakıt tüketiminin en küçüklemesi amaçlanmıştır. Bu amaç fonksiyonları hem tek başlarına hem de birlikte ele alınarak oluşturulan referans durum ile karşılaştırılmıştır. Test problemlerinden elde edilen sonuçlara göre gecikmeden kaynaklı toplam yakıt tüketiminde ve toplam gecikme süresinde referans duruma göre $\% 17,3$ ve $\% 3,2$ oranlarında iyileşmeler meydana gelmiştir. Her iki amaç fonksiyonun birlikte ele alındığı durumda ise yakıt tüketiminde \%15,2 oranında bir azalma saptanmıştır.

\section{Anahtar Kelimeler}

"Uçak çaklşma saptama ve çözümleme, Hava trafik yönetimi, karma tam-sayıl doğrusal programlama, yakıt tüketimi, gecikme süresi”

\begin{abstract}
An increasing demand in air transportation leads to a significant rise in traffic density both at airspaces and at airports. This rise in air traffic density may cause both delays and conflicts between aircraft pairs. Aircraft conflict detection and resolution problem is discussed in this study and a mixed integer linear programming model is proposed for this problem. A baseline case was generated to test the proposed mathematical model. The baseline case decides which aircraft receive delay for the resolution of conflicts, with the principle of the first come first served. The proposed model minimizes total delay time and total fuel consumption due to delay. These objectives were compared with the baseline considering the functions both individually and together. According to the results, the enhancement of the total fuel consumption due to delay and total delay duration are $17.3 \%$ and $3.2 \%$ compared to the baseline cases. When the two functions are considered together, $15.2 \%$ reduction in fuel consumption was obtained.
\end{abstract}

\section{Key Words}

"Aircraft conflict detection and resolution, air traffic management, mixed integer linear programming, fuel consumption, airborne delay" 


\section{Giris}

Hava taşımacılığına artmakta olan talep ile hava trafik sayılarında da artış meydana gelmiştir. Bu durum mevcut hava trafiğin yönetilmesini daha da karmaşık bir hale getirerek uçaklar arasındaki emniyetli ayırma ihlali oluşmasına ve hava trafik kontrolörlerinin iş yüklerinin artmasına neden olmaktadır. Artan hava aracı sayısı uçaklar arasındaki çakışmaların saptanması ve çözümlenmesi için gelişmiş teknolojik aletlere olan ihtiyaç her geçen gün artırmaktadır. Uçaklar arasındaki emniyetli ayırma mesafesi yol aşaması hava sahaları için yatay düzlemde 5 deniz mili $(\mathrm{nm})$ ve dikey düzlemde de 1000 feet olarak kabul edilmektedir. (ICAO, 2007) Oluşabilecek çakışmalar ise hava trafik kontrolörlerinin müdahaleleri ile önlenmektedir. Bu müdahaleler baş açısı değişikliği, hız değişikliği ve irtifa değişimi olarak üç farklı talimat ile gerçekleşebilmektedir. Her bir tekniğin kullanılmasında uçak performans kısıtları ve hava trafiğinin durumu büyük önem arz etmektedir. Uçak çakışma saptama ve çözümleme konusu hava trafiğinin emniyetli ve verimli bir şekilde sürdürülmesi için çok önemlidir.

Uçak çakışma saptama ve çözümleme konusunda günümüze kadar birçok çalışma yapılmıştır. Bu çalışmada uçak çakışma saptama ve çözümleme problemine matematiksel bir model önerildiği için aşağıda incelenen çalışmalar bu konu hakkında olacaktır. Kuchar ve Yang (2000) yayınladıkları derleme makalesinde bu konu hakkında 2000 yılına kadar yapılmış olan çalışmaları sunmuşlardır. Benzer bir şekilde, Martin Campo (2010) yaptığı bir çalışmada 2010 yılına kadar olan uçak çakışma saptama ve çözümleme çalışmaları hakkında detaylı bir bilgi vermiştir. Richards ve How (2002) bu problemin çözümü için karma tam sayılı doğrusal bir model önererek uçakların yörüngeleri boyunca hangi noktalar üzerinden geçeceklerine karar vererek uçaklar arasında emniyetli ayırmanın sağlanmasını amaçlamıştır. Pallottino vd. (2002) karma tam sayılı doğrusal bir model geliştirerek uçakların arasındaki ayırmaları uçak pozisyonlarının geometrik yapısına bağlı olarak ya hız kısarak ya da baş açısı değişikliği uygulayarak sağlamıştır. Christodoulou ve Costoulakis (2004) ise Pallottino vd. (2002)' nin önerdiği modeli geliştirerek uçaklar arasındaki çakışmaları hem baş açısı hem de hız değişikliği yöntemi ile engellemiştir. Bu model küçük boyutlu test problemleri üzerinde denenmiştir. Vela vd. (2009) karma tam sayılı doğrusal bir model önererek uçak çakışmaları için hız ve irtifa değişikliklerini bir arada kullanmıştır. Bu modelde uçakları bütün hava sahasında kontrol etmeden sadece potansiyel çakışma noktalarında kontrol ederek çakışmaların saptanması ve çözümlenmesi sağlanmıştır. Alonso Ayuso vd. (2012, 2016a), uçak çakışma saptama ve çözümleme probleminin çözümü için iki farklı karma tam sayılı doğrusal olmayan model önermiş̧ir. Bu çalışmaların birincisinde sadece hız değiş̧ikliği yöntemini kullanarak ivmelenmenin en küçüklenmesini amaçlamış diğerinde ise sadece baş açısı değişikliği yöntemini kullanarak uçakların tekrar orijinal yörüngesine dönmesi sağlanmıştır. Bunlara ek olarak, Alonso Ayuso vd. (2016b) ayrıca çok amaçlı karma tam sayılı doğrusal olmayan bir model önerisinde de bulunmuştur. Bu model hız değişikliği, baş açısı değişikliği ve irtifa değişikliği yöntemlerini hep birlikte kullanmıştır. $\mathrm{Bu}$ çalışmada, hedef programlar yardımıyla sırasıyla toplam hız değişikliğini, toplam baş açısı değişikliğini ve toplam irtifa değişikliğini en küçüklemeye çalışmıştır. Cafieri ve Durand (2014) uçak çakışmalarını önlemek için karma tam sayılı doğrusal olmayan bir model önermiş ve sadece hız değiş̧ikliği yöntemini kullanmıştır. Ayrıca problemin karmaşıklığından dolayı sezgisel bir yöntem de önermişlerdir. Cafieri ve Rey (2017) Cafieri ve Durand (2014)'dan farklı bir MINLP modeli sunmuşlardır. Çakışmanın olmadığı en büyük uçak setini elde etmeyi bunu da hız değişikliği manevrası kullanarak yapmayı amaçlamışlardır. Benzer bir şekilde, Cafieri ve Omheni (2017) baş açısı ve hız değişikliği yöntemlerini sırayla kullanan başka bir karma tam sayılı doğrusal olmayan bir model sunmuşlardır. Elde edilen sonuçlara göre, her iki manevranın birlikte kullanılmasının çakışma çözümüne olumlu bir katkı yaptığı gözlemlenmiştir. Hong ve arkadaşları (2017), baş açısı ve hız değişikliği yöntemlerini kullanan karma tam sayılı doğrusal olmayan bir model önermiştir. Bu modelde, çakışmaları çözümlemek için parçacık sürüsü algoritmasını kullanmıştır. Çeçen ve Çetek (2019) uçak çakışma saptama ve çözümleme problemi için iki aşamalı bir matematiksel model önermişlerdir. Bu modelin ilk aşamasında çoklu giriş noktası yaklaşımını kullanılarak mevcut çakışmaların çözümlenmesi ve bu yaklaşımın bütün çakışmaların çözümünde yeterli olmaması durumunda ise çözümlenemeyen çakışmaların çözümleme sürelerinin en küçüklenmesi amaçlanmıştır. Ayrıca, ilk aşamada çözüme ulaşmak için hem genetik algoritma hem de yasaklı arama algoritması kullanılmıştır. İkinci aşamada ise çözümlenemeyen çakışmalar için çakışan uçaklara bir vektör manevrası yaptırılarak tüketilen yakıtın en küçüklenmesi sağlanmıştır. Cai ve Zhang (2019) uçak çakışma saptama ve çözümleme konusunda karma tam sayılı doğrusal olmayan bir model geliştirmiş ve modelde irtifa ve hız değişimlerini kullanarak uçaklar arasındaki emniyetli ayırmayı sağlamıştır. Model büyük boyutlu problemleri kesin çözüm garanti eden çözücülerle kısa süre içinde çözmeyi başarmıştır. Çeçen ve Çetek (2020), Çeçen ve Çetek (2019)'den farklı olarak çoklu giriş noktası yaklaşımını hız değişikliği yöntemi ile birleştirterek karma tam sayılı doğrusal bir model önermiş ve problemin çözümü için sezgisel bir algoritma geliştirmişlerdir. Bu modelde toplam giriş noktası değişikliği, toplam hız değeri değişikliği ve çakışma çözümleri için gerekli toplam sürenin tek bir amaç fonksiyonu halinde en küçüklenmesi hedeflenmiştir. Model çok sayıda test problemi üzerinde test edilmiş ve giriş noktası değişikliğinin hız değişimi ile kullanılması durumunda bütün çakışmaların çözümlendiği belirtilmiştir. Çeçen vd. (2020) seyir aşamasındaki uçakların çakışmalarının önlenmesi için iki aşamalı bir matematiksel model önermişlerdir. Modelin ilk aşamasında uçakların irtifa değişimi sayesinde çakışmalardan kaçınması hedeflenmiştir. Eğer bu çözüm yöntemi yeterli olmaz ise, ikinci aşamada ise irtifa değişikliği yapılmadan sadece vektör manevrası yapılarak çakışmaların çözümlenmesi amaçlanmıştır. Modelin çözümü için ise tavlama benzetimi algoritması kullanılmıştır.

Bu çalışmada, uçak çakışma saptama ve çözümleme probleminin çözümü için karma tam sayılı doğrusal programlama modeli önerilmiştir. Önerilen modelde uçakların seyir aşamasında bulunduğu ve çakışma çözümlerinin vektör manevrası yardımı ile yapıldığı kabul edilmiştir. $\mathrm{Bu}$ manevradan dolayı uçakların maruz kalacakları toplam gecikme süreleri ile gecikmeden kaynaklı toplam yakıt tüketimlerinin hem ayrı ayrı hem de birlikte en küçüklenmesi amaçlanmıştır. Önerilen modelin test edilmesi için bir referans durum hazırlanmıştır. Bu referans durumda ilk gelen ilk hizmet alır (First In First Out-FIFO) prensibi kabul edilerek çakışma noktasına ilk gelen uçağa herhangi bir gecikme uygulanmadan, ikinci gelen uçağa ise gerekli gecikmenin verilmesi için vektör manevrası 
yaptırılmaktadır. Ayrıca çalışmada çok sayıda uçak çeşidi kullanılarak hız ve yakıt tüketim değerlerindeki farklılıkların amaç fonksiyonları üzerindeki etkisinin görülmesi hedeflenmiştir. Önerilen bu model ile farklı amaç fonksiyonlarının referans duruma göre nasıl bir değişiklik meydana getirdiği hesaplanarak sunulmuştur.

Makalenin 2. bölümünde ele alınan problem tanıtılmış, 3. bölümde önerilen matematiksel model takdim edilmiş, 4. bölümde deneysel sonuçlar sunulmuş ve son bölümde ise bulunan sonuçlar tartışılmıştır.

\section{Problemin Tanıtılması}

Uçak çakışma saptama ve çözümleme problemi hava trafiğinin emniyetli bir şekilde sunulması için çok önemlidir. Bu problem havaalanlarında, terminal kontrol sahalarında ve saha kontrol merkezlerinde yaşanabilmektedir. Havaalanlarında uçaklar arasın da iniş ve kalkış operasyonlarının düzenlenmesinde ve yerdeki hareketlerinde emniyetli ayırma ihlali meydana gelebilmektedir. Benzer bir şekilde, terminal hava sahalarında ise uçakların iniş sıralaması yapılırken emniyetli ayırma ihlalleri oluşabilmektedir. Saha kontrolü ise uçakların seyir uçuşlarını gerçekleştirdiği hava sahalarıdır. Bu bölüm toplam hava sahaları içinde en büyük bölümü oluşturmaktadır. $\mathrm{Bu}$ hava sahalarında iki farklı çakışma durumu meydana gelebilmektedir bunlar aynı ve kesişen rota çakışmalarıdır. Bu çalışmada uçak çakışma saptama ve çözümleme probleminin saha kontrol merkezinde gerçekleştiği kabul edilmiştir. Önerilen modelde amaç fonksiyonları arasındaki ilişkinin ortaya konması için basit ve kesişen bir hava sahası yapısı kullanılmıştır (Şekil 1).

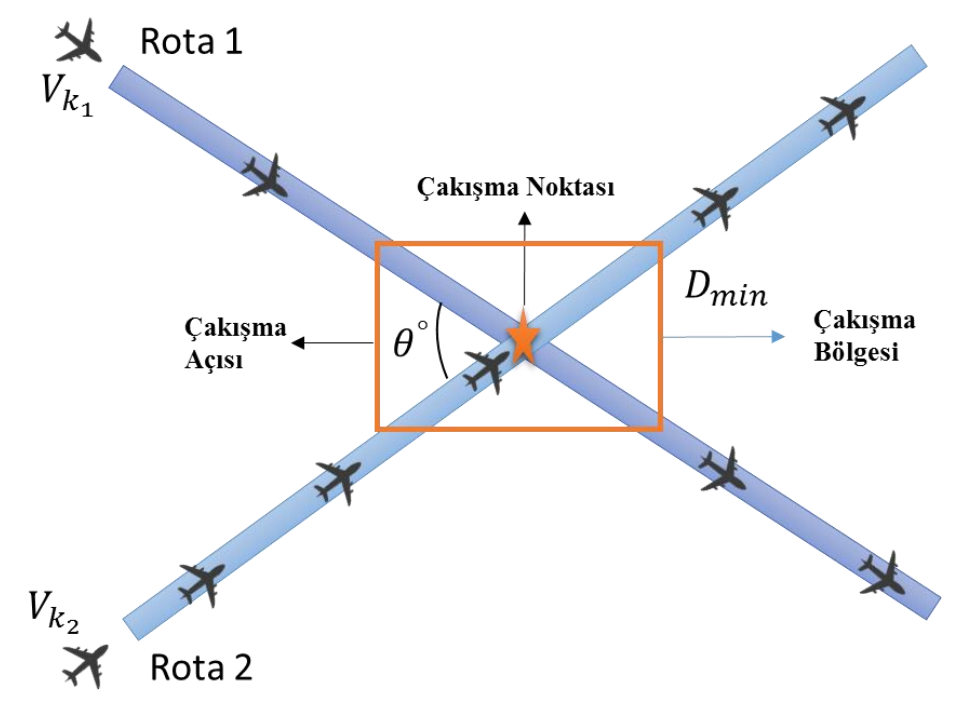

Şekil 1. Önerilen hava sahasının bir uçuş seviyesi için görünümü

Şekil 1' de görüleceği üzere kullanılan hava sahasında iki farklı rota, beş farklı uçuş seviyesi (FL) ve her bir irtifa için bir kesişme noktası bulunmaktadır. Uçakların rota bilgileri, giriş ve çıkış noktaları ve uçuş seviyeleri modele parametre olarak eklenmektedir. Her iki rotanın uzunluğu 100 nautical mile (NM) ve kesişme noktasına olan uzaklıkları ise 50 NM olarak belirlenmiştir. Uçakların farklı rotaları kullanmaları durumunda ise ortak bir çakışma noktasına uğrayarak seyahatlerine devam etmeleri gerekmektedir. Uçaklar arasında emniyetli ayırma mesafesi, $\mathrm{D}_{\min }, 5 \mathrm{NM}$ olarak kabul edilmiştir. Uçaklar arasındaki emniyetli ayırma mesafelerinin korunması için zaman ayırması yöntemi kullanılmaktadır. Aynı rotadaki çakışmalar hem giriş noktasında hem de çıkış noktasında kontrol edilmektedir. Bu yöntem ile uçakların birbirlerini geçmesi engellenmiştir. Kesişen rotalarda bulunan iki uçak arasındaki emniyetli ayırma zaman1,

$$
T_{k_{1} k_{2} j}=\frac{D_{\min }}{V_{k_{1} j} V_{k_{2} j}|\sin (\theta)|} \sqrt{\left(V_{k_{1} j}\right)^{2}+(V j)^{2}-2 V_{k_{1} j} V_{k_{2} j} \cos (\theta)}
$$

$T_{k_{1} k_{2} j}$, uçaklar arasındaki çakışma açısına , $\theta$, ve uçakların hızlarına, $V_{k_{1} j}, V_{k_{2} j}$, göre değişmektedir (Carlier vd. (2013)). Bu çalışmada her bir uçuş seviyesi için kesişme açısı sabittir. Bu çalışmada üretilen bütün senaryolarda referans durum ile önerilen modellerin sonuçların karşılaştırılmasında kullanılmak üzere dar gövdeli (DG) ve geniş gövdeli (GG) uçak tiplerinden oluşan on farklı uçak çeşidi bulunmaktadır. Her bir uçak tipi 5 farkı uçak çeşidi bulundurmaktadır. Uçaklar arasındaki emniyetli ayırma zamanını uçakların çeşitleri etkilemektedir çünkü her bir uçağın uçuş hızı farklı olduğu için aynı performans kategorisine sahip olan farklı uçak çiftleri arasında farklı zaman ayırmaları gerekebilmektedir. Yapılan çalışmada ise FL290 (uçuş seviyesi 29000 feet), FL310, FL330, FL350 ve FL370 uçuş seviyeleri kullanılmıştır. Her bir seviyede uçak hızları ve yakıt tüketimleri BADA 3.11'de belirtilen operasyonel hızlar olarak seçilmiştir ve Tablo I' de sunulmuştur. 
Tablo I. Uçakların farklı uçuş seviyeleri için uçuş hızları (NM/saat) ve yakıt tüketim değerleri (kg/dakika)

\begin{tabular}{cccccc}
\hline Uçak Çeşidi & FL290 & FL310 & FL330 & FL350 & FL370 \\
\hline DG1 & $462 / 44,9$ & $458 / 42,4$ & $454 / 40,2$ & $450 / 38,4$ & $447 / 36,3$ \\
DG2 & $431 / 43$ & $444 / 43,2$ & $454 / 42,6$ & $450 / 42,6$ & $447 / 40,5$ \\
DG3 & $459 / 43,6$ & $458 / 41,1$ & $454 / 38,4$ & $450 / 38,4$ & $447 / 36$ \\
DG4 & $459 / 54,6$ & $458 / 52,1$ & $454 / 49,6$ & $450 / 49,6$ & $447 / 47,4$ \\
DG5 & $444 / 35,5$ & $440 / 33,4$ & $436 / 31,6$ & $432 / 31,6$ & $430 / 30,1$ \\
GG1 & $485 / 108,7$ & $481 / 101,7$ & $477 / 95,3$ & $473 / 95,5$ & $470 / 90$ \\
GG2 & $473 / 89,1$ & $469 / 85$ & $465 / 81,4$ & $461 / 78,4$ & $459 / 70,2$ \\
GG3 & $485 / 110,7$ & $481 / 104,2$ & $477 / 110,7$ & $473 / 93,7$ & $470 / 89,8$ \\
GG4 & $497 / 179,4$ & $493 / 170,9$ & $489 / 163,7$ & $484 / 158$ & $482 / 153,8$ \\
GG5 & $473 / 115,3$ & $487 / 115,8$ & $489 / 111,6$ & $484 / 106,4$ & $482 / 102,3$ \\
\hline
\end{tabular}

Uçakların doğuya doğru gittiği, rüzgâr hızının $0 \mathrm{NM}$ /saat olduğu, uçuşları sırasında hız ve irtifa değişikliği yapmadığı kabul edilmiştir.

\section{Matematiksel Model}

Uçak çakışma saptama ve çözümleme probleminin çözümü için önerilen karma tam sayılı doğrusal modelde toplam gecikme süresi ve gecikmeden kaynaklı toplam yakıt tüketiminin ayrı ayrı ve birlikte olarak 3 farklı amaç fonksiyonu halinde en küçüklenmesi amaçlanmıştır. Üçüncü amaç fonksiyonu ise ağılıklı toplam yöntemi kullanılarak her iki amaç fonksiyonun kullanılması ile hesaplanmıştır. Ayrıca, her iki amaç fonksiyonu için ağırlıklar $e_{1}=0.5$ ve $e_{2}=0.5$ olarak belirlenmiştir. Amaç fonksiyonu (18)'de verilen her iki amaç fonksiyonun birimleri arasındaki farklılıkların ortadan kaldırılması için normalleştirilme işlemi uygulanmıştır ve bu sayede amaç fonksiyonları 0 ile 1 arasında bir değer alabilir bir hale dönüştürülmüş̧ür. Normalleştirme işlemini uygulamadan önce ise amaç fonksiyonlarının ideal ve nadir noktaları bulunmuştur. Amaç fonksiyonları (16) ve (17) kısıt (2) -(13) arasındaki kısıtları kullanarak sırası ile $w_{\min } v e y_{\min }$ değerleri hesaplanmıştır. Amaç fonksiyonu (18)'in hesaplanması için nadir noktaları $\mathrm{w}_{\max }$ ve $\mathrm{y}_{\max }$ amaç fonksiyonu (16) için kısıtlar (2) -(13), (15)'i ve amaç fonksiyonu (17) için ise kısıtlar (2) -(13), (14)'ü kullanılarak sırası ile hesaplanmıştır.

\section{1. İndisler}

$$
i, i_{1}, i_{2} \quad: \text { Uçak }(i=1, \ldots ., n)
$$

\subsection{Parametreler}

\begin{tabular}{|c|c|}
\hline & \\
\hline$n$ & : Uçak sayısı \\
\hline$l_{1}$ & : Rotaların kesişme noktasına olan uzaklığı \\
\hline$l_{2}$ & : Uçuş rotalarının uzunluğu \\
\hline$v_{A_{i} F_{i}}$ & $: A_{i}$. uçak çeşidinin $F_{i}$. uçuş seviyesindeki hızı \\
\hline$r_{i}$ & : i. uçağın hangi rotayı kullandığı bilgisi \\
\hline$g_{i}$ & : i. uçağın hava sahasına beklenen giriş zamanı \\
\hline$A_{i}$ & : i. uçağın hangi uçak çeşidi olduğu bilgisi \\
\hline$F_{i}$ & : i. uçağın hangi uçuş seviyesinde olduğu bilgisi \\
\hline$y t_{A_{i} F_{i}}$ & $: A_{i}$. uçak çeşidinin $F_{i}$. uçuş seviyesindeki birim zamandaki yakıt tüketimi \\
\hline$w_{\max }$ & : en küçük toplam gecikme süresi için elde edilen toplam yakıt tüketiminin değeri \\
\hline$y_{\max }$ & : en küçük toplam yakıt tüketimi için elde edilen toplam gecikme süresinin değeri \\
\hline$w_{\min }$ & : en küçük toplam yakıt tüketimi \\
\hline$y_{\min }$ & : en küçük toplam gecikme süresi \\
\hline$e_{1}$ & : ağırlık katsayısı \\
\hline$e_{2}$ & : ağırlık katsayısı \\
\hline$T_{A_{i_{1}} A_{i_{2}} F_{i}}$ & : Aynı rota kullanan uçaklar için, $A_{i_{1}}$.uçak çeşidi ile $A_{i_{2}}$. Uçak çeşidi arasında $F_{i}$. uçuş seviyesindeki zaman ayırması \\
\hline$S_{A_{i_{1}} A_{i_{2}} F_{i}}$ & $\begin{array}{l}\text { :Farklı rotaları kullanan uçaklar için, } A_{i_{1}} \text {.uçak çeşidi ile } A_{i_{2}} \text {. Uçak çeşidi arasında } F_{i} \text {. uçuş seviyesindeki kesişme } \\
\text { noktasındaki zaman ayırması }\end{array}$ \\
\hline
\end{tabular}

\subsection{Karar Değiş̧kenleri}

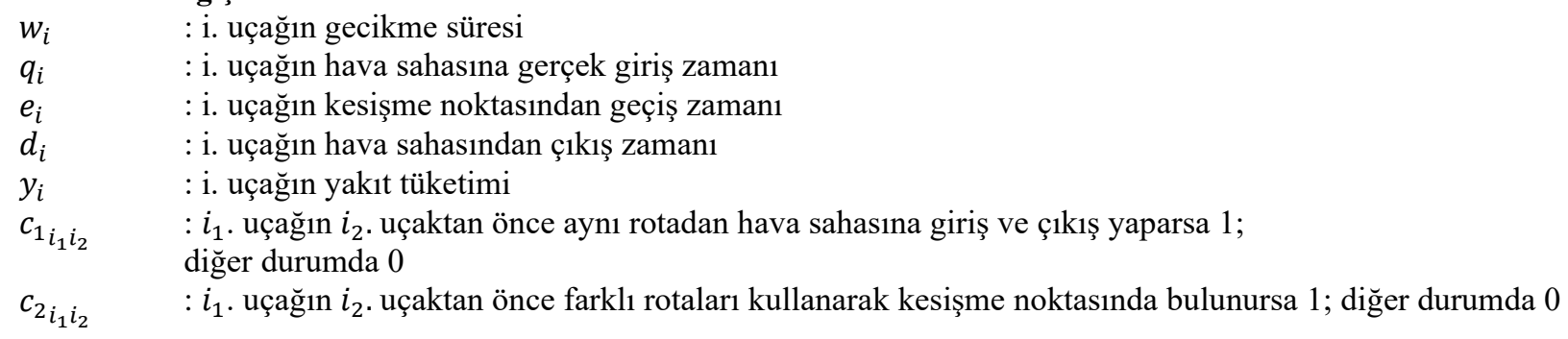




\subsection{Kisitlar}

(2), (3) ve (4) No.lu kısıtlar sırasıyla uçakların hava sahasına gerçek giriş zamanı ve gecikme süresini, kesişme noktasında bulunma zamanını ve hava sahasından çıkış zamanı hesaplamaktadır.

$$
\begin{aligned}
& q_{i}=g_{i}+w_{i} \forall i \\
& e_{i}=g_{i}+\frac{l_{1}}{v_{A_{i} F_{i}}} \forall i \\
& d_{i}=g_{i}+\frac{l_{2}}{v_{A_{i} F_{i}}} \forall i
\end{aligned}
$$

(5), (6), (7) ve (8) No.lu kısıtlar sırasıyla aynı rotayı ve aynı uçuş seviyesini kullanan uçaklar arasındaki hem giriş hem de çıkış noktasında kontrol ederek uçaklar arasındaki emniyetli ayırmayı sağlar. Model $c_{1_{i_{1}}, i_{2}}$ karar değişkini sayesinde hangi uçağın hava sahasına ilk giriş ve çıkış yapacağına karar vermektedir. $c_{1_{i_{1}, i_{2}}}$ karar değişkenin 1 değerini alması durumunda (5) ve (6) kısıtlar $i_{1}$. uçağın $i_{2}$. Uçağa göre daha önce hava sahasına girmesine ve çıkış yapmasına imkân vereceklerdir.

$$
\begin{aligned}
& q_{i_{2}}-q_{i_{1}} \geq T_{A_{i_{1}} A_{i_{2}} F_{i_{1}}}-\left(1-c_{1_{i_{1}, i_{2}}}\right) M \forall i_{1}, i_{2} \quad \mid i_{1} \neq i_{2}, \quad F_{i_{1}}=F_{i_{2}}, r_{i_{1}}=r_{i_{2}} \\
& q_{i_{1}}-q_{i_{2}} \geq T_{A_{i_{2}} A_{i_{1}} F_{i_{1}}}-\left(c_{1_{i_{1}, i_{2}}}\right) M \forall i_{1}, i_{2} \mid i_{1} \neq i_{2}, F_{i_{1}}=F_{i_{2}}, r_{i_{1}}=r_{i_{2}} \\
& d_{i_{2}}-d_{i_{1}} \geq T_{A_{i_{1}} A_{i_{2}} F_{i_{1}}}-\left(1-c_{1_{i_{1}, i_{2}}}\right) M \forall i_{1}, i_{2} \quad \mid i_{1} \neq i_{2}, \quad F_{i_{1}}=F_{i_{2}}, r_{i_{1}}=r_{i_{2}} \\
& d_{i_{1}}-d_{i_{2}} \geq T_{A_{i_{2}} A_{i_{1}} F_{i_{1}}}-\left(c_{1_{i_{1}, i_{2}}}\right) M \forall i_{1}, i_{2} \quad \mid i_{1} \neq i_{2}, \quad F_{i_{1}}=F_{i_{2}}, r_{i_{1}}=r_{i_{2}}
\end{aligned}
$$

(9) ve (10) No.lu kısıtlar sırasıyla farklı rotaları ve aynı uçuş seviyesini kullanan uçaklar arasındaki emniyetli ayırmayı kesişme noktası üzerinde kontrol ederek sağlar.

$$
\begin{aligned}
& e_{i_{2}}-e_{i_{1}} \geq S_{A_{i_{1}} A_{i_{2}} F_{i_{1}}}-\left(c_{2 i_{1}, i_{2}}\right) M \forall i_{1}, i_{2} \quad \mid i_{1} \neq i_{2}, F_{i_{1}}=F_{i_{2}}, r_{i_{1}} \neq r_{i_{2}} \\
& e_{i_{1}}-e_{i_{2}} \geq S_{A_{i_{2}} A_{i_{1}} F_{i_{1}}}-\left(1-c_{2 i_{1}, i_{2}}\right) M \forall i_{1}, i_{2} \quad \mid i_{1} \neq i_{2}, F_{i_{1}}=F_{i_{2}}, r_{i_{1}} \neq r_{i_{2}}
\end{aligned}
$$

(11) No.lu kısıt uçakların gecikme sürelerinin $\left(w_{i}\right)$ sağlanması için yaptıkları vektör manevrasında harcadıkları yakıt tüketimlerini $\left(y_{i}\right)$ hesaplamaktadir.

$$
y_{i}=f_{i} \cdot y t_{A_{i} F_{i}} \quad \forall i
$$

(12) ve (13) No.lu kısıtlar işaret kısıtlarıdır.

$$
\begin{array}{cc}
w_{i}, q_{i}, e_{i}, d_{i}, y_{i} \geq 0 & \forall i \\
c_{1_{i_{1}}, i_{2}}, c_{2_{i_{1}, i_{2}}} \in\{0,1\} & \forall i_{1}, i_{2} \\
\sum_{i=1}^{n} w_{i} \leq w_{\text {min }} & \\
\sum_{i=1}^{n} y_{i} \leq y_{\text {min }} &
\end{array}
$$

\subsection{Amaç Fonksiyonu}

(16), (17) ve (18) No.lu amaç fonksiyonları sırasıyla toplam gecikmeyi, gecikmeden kaynaklı toplam yakıt tüketimini ve her iki amaç fonksiyonun birlikte hesaplanmasını sağlamaktadır. Bütün amaç fonksiyonları modelde kullanılmıştır. Üç farklı amaca göre hesaplanan sonuçlar deneysel sonuçlar bölümünde sunulmuştur.

$$
\text { enk } \sum_{i=1}^{n} w_{i}
$$




$$
\begin{gathered}
\text { enk } \sum_{i=1}^{n} y_{i} \\
\text { enk } e_{1} \cdot\left(\sum_{i=1}^{n} \frac{w_{i}}{w_{\max }}\right)+e_{2} \cdot\left(\sum_{i=1}^{n} \frac{y_{i}}{y_{\max }}\right)
\end{gathered}
$$

\section{Deneysel Sonuçlar}

Önerilen karma tam sayılı doğrusal programlama modelin test edilmesi için 30 farklı senaryo oluşturulmuştur. Trafik sayısı bütün uçuş seviyeleri için toplam 100 uçak olarak belirlenmiştir. Uçakların uçuş seviyeleri, uçak çeşitleri ve rotaları normal dağılıma göre, hava sahasına giriş zamanları ise üstel dağılıma göre belirlenmiştir ve senaryolarda kullanılan ilgili değerler Tablo II' de sunulmuştur. Tüm testler Intel (R) Core (TM) i7 CPU@2.3 GHz işlemcisi, 16 GB belleği olan bir bilgisayarda yapıllmıştır.

\begin{tabular}{|c|c|c|c|c|c|c|c|c|c|c|c|c|c|c|c|c|c|}
\hline \multirow{2}{*}{ Senaryo } & \multicolumn{10}{|c|}{ Uçak çeşidine göre bulunan uçak sayısı } & \multicolumn{5}{|c|}{ Uçak seviyesi sayısı } & \multicolumn{2}{|c|}{ Rota sayısı } \\
\hline & 1 & 2 & 3 & 4 & 5 & 6 & 7 & 8 & 9 & 10 & 1 & 2 & 3 & 4 & 5 & 1 & 2 \\
\hline 1 & 11 & 9 & 7 & 18 & 12 & 5 & 6 & 8 & 12 & 12 & 24 & 14 & 17 & 27 & 18 & 38 & 62 \\
\hline 2 & 6 & 13 & 14 & 16 & 5 & 10 & 7 & 9 & 11 & 9 & 19 & 17 & 20 & 21 & 23 & 56 & 44 \\
\hline 3 & 10 & 10 & 11 & 8 & 10 & 14 & 8 & 13 & 10 & 6 & 12 & 23 & 18 & 26 & 21 & 46 & 54 \\
\hline 4 & 12 & 9 & 11 & 9 & 9 & 14 & 10 & 7 & 12 & 7 & 22 & 21 & 18 & 20 & 19 & 56 & 44 \\
\hline 5 & 12 & 8 & 9 & 8 & 15 & 6 & 10 & 3 & 14 & 15 & 17 & 24 & 22 & 17 & 20 & 49 & 51 \\
\hline 6 & 7 & 12 & 10 & 12 & 9 & 15 & 6 & 10 & 9 & 10 & 22 & 21 & 20 & 18 & 19 & 51 & 49 \\
\hline 7 & 8 & 15 & 10 & 10 & 7 & 10 & 7 & 13 & 11 & 9 & 17 & 18 & 12 & 23 & 30 & 46 & 54 \\
\hline 8 & 6 & 11 & 9 & 9 & 12 & 13 & 9 & 10 & 8 & 13 & 25 & 19 & 13 & 27 & 16 & 51 & 49 \\
\hline 9 & 9 & 11 & 13 & 13 & 9 & 9 & 14 & 6 & 8 & 8 & 19 & 16 & 27 & 18 & 20 & 52 & 48 \\
\hline 10 & 11 & 7 & 10 & 10 & 14 & 10 & 10 & 8 & 7 & 13 & 18 & 25 & 22 & 19 & 16 & 55 & 45 \\
\hline 11 & 9 & 8 & 9 & 10 & 13 & 11 & 7 & 4 & 13 & 16 & 20 & 19 & 21 & 26 & 14 & 51 & 49 \\
\hline 12 & 12 & 10 & 10 & 9 & 7 & 10 & 13 & 13 & 6 & 10 & 25 & 15 & 31 & 13 & 16 & 45 & 55 \\
\hline 13 & 6 & 9 & 11 & 12 & 8 & 11 & 14 & 8 & 12 & 9 & 14 & 21 & 24 & 20 & 21 & 61 & 39 \\
\hline 14 & 16 & 10 & 13 & 12 & 10 & 5 & 11 & 7 & 8 & 8 & 21 & 23 & 17 & 21 & 18 & 43 & 57 \\
\hline 15 & 9 & 10 & 7 & 12 & 11 & 12 & 10 & 8 & 7 & 14 & 21 & 20 & 18 & 24 & 17 & 55 & 45 \\
\hline 16 & 13 & 11 & 11 & 6 & 11 & 10 & 13 & 8 & 6 & 11 & 22 & 29 & 14 & 22 & 13 & 59 & 41 \\
\hline 17 & 14 & 13 & 9 & 12 & 13 & 6 & 8 & 7 & 10 & 8 & 7 & 22 & 20 & 24 & 27 & 56 & 44 \\
\hline 18 & 9 & 15 & 14 & 6 & 11 & 5 & 8 & 12 & 12 & 8 & 18 & 21 & 23 & 22 & 16 & 49 & 51 \\
\hline 19 & 6 & 8 & 10 & 10 & 9 & 13 & 15 & 12 & 7 & 10 & 21 & 14 & 23 & 16 & 26 & 43 & 57 \\
\hline 20 & 9 & 11 & 6 & 9 & 14 & 10 & 7 & 10 & 17 & 7 & 25 & 22 & 18 & 15 & 20 & 39 & 61 \\
\hline 21 & 10 & 7 & 13 & 12 & 9 & 9 & 10 & 4 & 11 & 15 & 22 & 18 & 21 & 24 & 15 & 41 & 59 \\
\hline 22 & 13 & 10 & 5 & 9 & 13 & 9 & 14 & 12 & 8 & 7 & 20 & 20 & 20 & 24 & 16 & 51 & 49 \\
\hline 23 & 12 & 14 & 7 & 9 & 15 & 6 & 12 & 7 & 10 & 8 & 21 & 24 & 25 & 19 & 11 & 50 & 50 \\
\hline 24 & 11 & 8 & 11 & 18 & 9 & 4 & 5 & 14 & 9 & 11 & 17 & 27 & 19 & 20 & 17 & 46 & 54 \\
\hline 25 & 8 & 6 & 10 & 14 & 13 & 14 & 12 & 11 & 6 & 6 & 19 & 27 & 16 & 15 & 23 & 54 & 46 \\
\hline 26 & 11 & 8 & 8 & 14 & 10 & 9 & 14 & 7 & 10 & 9 & 31 & 17 & 15 & 18 & 19 & 51 & 49 \\
\hline 27 & 10 & 8 & 12 & 15 & 8 & 10 & 7 & 12 & 13 & 5 & 21 & 20 & 21 & 18 & 20 & 51 & 49 \\
\hline 28 & 8 & 10 & 10 & 8 & 8 & 7 & 13 & 11 & 8 & 17 & 19 & 25 & 19 & 18 & 19 & 60 & 40 \\
\hline 29 & 11 & 12 & 9 & 13 & 7 & 10 & 10 & 13 & 9 & 6 & 21 & 16 & 19 & 16 & 28 & 43 & 57 \\
\hline 30 & 5 & 8 & 12 & 12 & 9 & 6 & 16 & 11 & 7 & 14 & 18 & 18 & 24 & 22 & 18 & 52 & 48 \\
\hline
\end{tabular}

Tablo II. Senaryo açıklamaları

Matematiksel model GAMS 23.3 ile kodlanmış, çözücü olarak CPLEX kullanılmıştır. Matematiksel modelin elde ettiği sonuçlar Tablo III' te gösterilmiş̧tir. Çizelgelerde ilk sütun senaryo numarasını, ikinci ve üçüncü sütunlar ilk gelen ilk hizmet alır yaklaşımı ile hazırlanan referans durumdaki yakıt $(\mathrm{kg})$ ve gecikme (saniye) sürelerini göstermektedir. Dördüncü ve beşinci sütunlar gecikmeden 
kaynaklı toplam yakıt tüketimini en küçüklendiği durumdaki yakıt ve gecikme sürelerini belirtmektedir. Altıncı ve yedinci sütunlar ise toplam gecikmenin en küçüklendiği durumdaki yakıt ve gecikme sürelerini göstermektedir. Son iki sütun ise toplam gecikmenin ve gecikmeden kaynaklı yakıt tüketimini birlikte en küçüklendiği yakıt ve gecikme sürelerini sunmaktadır.

Tablo III. Her bir amaç fonksiyonu için yakıt tüketimi (kg) ve gecikme (saniye) süreleri

\begin{tabular}{|c|c|c|c|c|c|c|c|c|}
\hline \multirow{2}{*}{ Senaryo } & \multicolumn{2}{|c|}{ Referans durum (FIFO) } & \multicolumn{2}{|c|}{$\begin{array}{l}\text { Gecikmeden kaynaklı } \\
\text { toplam yakıtın en } \\
\text { küçüiklenmesi }\end{array}$} & \multicolumn{2}{|c|}{$\begin{array}{l}\text { Toplam gecikmenin en } \\
\text { küçüklenmesi }\end{array}$} & \multicolumn{2}{|c|}{$\begin{array}{c}\text { Gecikmeden kaynaklı } \\
\text { toplam yakıtın ve toplam } \\
\text { gecikmenin birlikte en } \\
\text { küçüklenmesi }\end{array}$} \\
\hline & Yakıt & Gecikme & Yakıt & Gecikme & Yakıt & Gecikme & Yakıt & Gecikme \\
\hline 1 & 1102.7 & 1009.7 & 1040.8 & 1044.1 & 1072.7 & 969.9 & 1051.2 & 990.2 \\
\hline 2 & 919.1 & 714.0 & 719.0 & 693.0 & 719.0 & 693.0 & 719.0 & 693.0 \\
\hline 3 & 740.4 & 574.9 & 591.0 & 612.4 & 674.7 & 574.9 & 618.9 & 578.7 \\
\hline 4 & 757.1 & 611.0 & 705.0 & 720.4 & 757.1 & 611.0 & 741.6 & 620.5 \\
\hline 5 & 531.2 & 445.3 & 476.7 & 484.1 & 531.2 & 445.3 & 496.1 & 465.7 \\
\hline 6 & 1191.0 & 919.3 & 924.1 & 1061.3 & 1064.2 & 780.5 & 1064.2 & 780.5 \\
\hline 7 & 945.4 & 821.2 & 842.3 & 925.5 & 945.4 & 821.2 & 904.5 & 835.5 \\
\hline 8 & 958.6 & 814.4 & 801.2 & 976.2 & 984.0 & 774.6 & 846.2 & 869.1 \\
\hline 9 & 916.4 & 844.4 & 916.4 & 844.4 & 917.4 & 820.3 & 917.4 & 820.3 \\
\hline 10 & 457.3 & 407.3 & 449.7 & 466.9 & 485.7 & 403.5 & 457.3 & 407.3 \\
\hline 11 & 1501.8 & 1089.6 & 974.2 & 1133.5 & 1282.7 & 1016.3 & 984.1 & 1082.9 \\
\hline 12 & 932.0 & 710.6 & 726.7 & 747.9 & 932.0 & 710.6 & 730.0 & 725.3 \\
\hline 13 & 1005.6 & 1068.0 & 882.2 & 1163.4 & 1005.6 & 1068.0 & 892.9 & 1118.1 \\
\hline 14 & 836.8 & 607.7 & 695.5 & 732.5 & 836.8 & 607.7 & 724.3 & 626.1 \\
\hline 15 & 658.5 & 522.3 & 532.0 & 536.5 & 654.7 & 522.3 & 532.0 & 536.5 \\
\hline 16 & 944.3 & 767.3 & 739.2 & 832.2 & 944.3 & 767.3 & 739.2 & 832.2 \\
\hline 17 & 818.9 & 910.6 & 716.8 & 956.3 & 776.1 & 855.9 & 739.6 & 857.5 \\
\hline 18 & 1623.3 & 1323.3 & 1156.2 & 1486.4 & 1524.2 & 1302.7 & 1160.9 & 1443.9 \\
\hline 19 & 618.3 & 515.0 & 493.2 & 596.5 & 618.3 & 515.0 & 493.2 & 596.5 \\
\hline 20 & 866.3 & 683.0 & 775.4 & 724.6 & 866.3 & 683.0 & 775.4 & 724.6 \\
\hline 21 & 844.9 & 498.1 & 712.3 & 602.2 & 844.9 & 498.1 & 747.6 & 559.9 \\
\hline 22 & 826.3 & 653.9 & 634.0 & 717.1 & 763.2 & 653.9 & 672.0 & 678.9 \\
\hline 23 & 955.7 & 962.3 & 825.6 & 1018.7 & 918.5 & 962.3 & 825.1 & 1017.8 \\
\hline 24 & 993.4 & 690.2 & 912.4 & 778.8 & 993.4 & 690.2 & 925.2 & 699.3 \\
\hline 25 & 1350.4 & 1156.7 & 1180.2 & 1178.8 & 1350.4 & 1156.7 & 1180.2 & 1178.8 \\
\hline 26 & 790.6 & 641.7 & 653.7 & 685.7 & 790.6 & 641.7 & 654.4 & 659.0 \\
\hline 27 & 1061.2 & 1048.1 & 728.4 & 961.7 & 873.7 & 914.6 & 728.4 & 961.7 \\
\hline 28 & 860.2 & 772.8 & 679.5 & 767.2 & 783.5 & 749.1 & 679.5 & 767.2 \\
\hline 29 & 978.8 & 930.1 & 688.8 & 910.8 & 803.3 & 777.1 & 758.7 & 812.2 \\
\hline 30 & 1197.6 & 783.5 & 1123.1 & 854.8 & 1135.0 & 753.5 & 1135.0 & 753.5 \\
\hline Ort. & 939.5 & 783.2 & 776.5 & 840.5 & 895.0 & 758.0 & 796.5 & 789.7 \\
\hline
\end{tabular}

Bu çalışmada referans durum ilk gelen ilk hizmeti alır yaklaşımı ile belirlenmiştir ve bu yaklaşım hava trafik kontrolörleri tarafından da kullanılmaktadır. Gecikmeden kaynaklı toplam yakıt tüketimini en küçüklendiği durumda ortalama yakıt tüketiminde referans duruma göre \%17,3 oranında bir azalma meydana gelmiştir buna karşın ortalama gecikme süresinde ise \%7,3 oranında bir artış yaşanmıştır. Ayrıca yakıt tüketim oranlarının 29 senaryoda referans duruma kıyasla daha iyi bir değer elde ettiği diğer kalan bir senaryoda ise referans durum ile aynı değere ulaştığı gözlemlenmiştir. Toplam gecikme süresinin sadece 4 senaryoda referans duruma göre daha iyi bir değer yakaladığı saptanmıştır. Buna ek olarak, toplam gecikmenin en küçüklendiği durumda ise ortalama gecikme süresinin referans duruma göre \%3,2 oranında azaldığı ve ortalama yakıt tüketiminin de referans duruma göre \%4,7 oranında azaldığı görülmüştür. Ayrıca toplam gecikme süresinin 13 senaryoda referans duruma kıyasla daha iyi bir değer elde ettiği diğer kalan bir 
senaryoda ise referans durum ile aynı değere ulaştığı görülmüştür. Ayrıca bu durumda gecikmeden kaynaklı yakıt tüketiminin 14 senaryoda referans duruma göre daha iyi bir değer yakaladığı saptanmıştır. Her iki amaç fonksiyonun birlikte en küçüklendiği durumda ise yakıt tüketiminde $\% 15,2$ oranında bir azalma meydana gelirken toplam gecikmenin $\% 0,8$ oranında arttığ görülmüştür. Gecikmeden kaynaklı yakıt tüketim değerleri referans duruma göre 28 senaryoda azalırken, gecikme süresi sadece 10 senaryoda iyileşmiştir. Bu durum zaten toplam gecikme sürelerinde farklı bir değişiklik yaşanmamasından kaynaklanmıştır. Bütün senaryoların çözüm süresi 10 saniyeyi geçmemektedir. Her bir senaryoda belirlenen çakışma sayıları Şekil 2'de sunulmuştur.

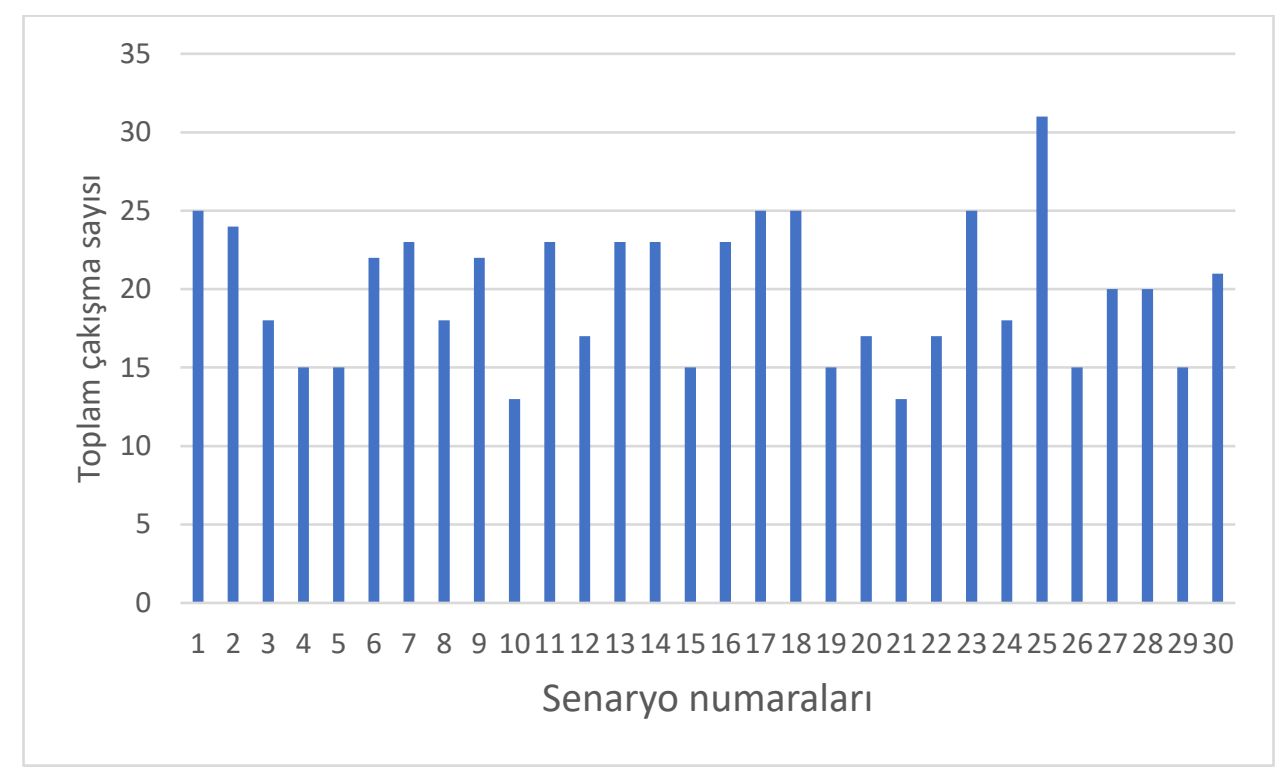

Şekil 2. Senaryolara göre toplam çakışma sayılarının dağılımı

Şekil 2'den de görüleceği üzere en fazla, ortalama ve en az çakışma sayısı sırasıyla 31, 20,3 ve 13 olarak hesaplanmıştır. Bu durumda her bir senaryoda uçakların yaklaşık \%20'sinin çakışmalardan kaçınmak için manevra yapması gerekmektedir.

\section{Sonuçlar}

Bu çalışmada uçak çakışma saptama ve çözümleme probleminin çözümü için karma tam sayılı doğrusal programlama modeli önerilmiş̧ir. Modelde toplam gecikme süresi ile gecikmeden kaynaklı yakıt tüketiminin ayrı ayrı ve birlikte en küçüklemesi amaçlanmıştır. Elde edilen sonuçların kıyaslanması için bir referans durum belirlenmiş̧ir ve bu durumda ilk gelene ilk hizmet verilir yaklaşımı ile çakışmalar çözümlenmiştir. Bu çalışmada çok sayıda uçak çeşidi kullanılmış olup hız ve yakıt tüketim değerlerinde olan farklılıklar amaç fonksiyonlarının arasındaki ilişkiyi daha iyi ortaya çıkarmaya yardımcı olmuştur. Deneysel sonuçlar incelendiği zaman, önerilen model toplam gecikme süresinde ve gecikmeden kaynaklı yakıt tüketiminde ayrı ayrı en küçüklendiği zaman referans duruma göre sırasıyla \%3,2 ve \% 17,3 oranlarında iyileştirmeler meydana getirmiştir. Her iki amaç fonksiyonu birlikte en küçüklendiği durumda ise yakıt tüketiminde $\% 15,2$ azalma yapmasına karşın toplam gecikme sürelerinde $\% 0,8$ oranında bir artışa neden olmaktadır. Önerilen bu model ile farklı amaç fonksiyonlarının ilk gelen ilk hizmeti alır yaklaşımına göre çok daha verimli sonuçların elde edildiği gözlemlenmiştir. Sonuçlar incelendiği zaman hangi uçağın gecikme alarak vektör manevrası uygulaması kararının gecikmeden kaynaklı toplam yakıt tüketimini gözle görülür bir şekilde arttırabileceği anlaşılmaktadır. Ayrıca, uçaklar arasındaki çakışmaların önlenmesi için yapılan manevralarda sadece hava sahası gecikmelerinin göz önünde tutulması hava sahasında daha fazla yakıt tüketilmesine ve böylece de çevreyi daha fazla etkilemesine sebep olabilmektedir. Bunların yanında çakışma çözüm manevralarında uçak yakıt tüketim değerlerinin karar verme süreçlerine dâhil edilmesinin ekonomik önemi bir kez daha ortaya çıkmaktadır. Gecikme sürelerinin artması ise hava sahası kapasitesinin azalmasına ve kontrolörlerin uçakları daha uzun süre izlemesine ve dolayısıyla da iş yüklerinin artmasına neden olmaktadır. Ayrıca, artan gecikme süreleri uçakların varış zamanlarında da gecikmeler yaratmakta olup varış havalimanındaki kapı atama ve taksi rota planlamalarının değişmesine yol açacaktır. Bunlara ek olarak, uçuş sürelerinin artması kabin ekibinin uçuş sürelerinin erken dolmasına neden olarak kabin ekiplerinin çizelgelerinde değişiklikler yaşanmasına yol açacaktır. $\mathrm{Bu}$ durum ise havayolu işletmecilerine ekstra bir maliyet ortaya çıkaracaktır. Bütün bu muhtemel sonuçlar incelediğinde ise her iki amaç fonksiyonunun birlikte ele alınarak tek bir amaç fonksiyonu haline dönüştürülmesi hem havayolu işletmecilerine oluşabilecek ek maliyetleri azaltılmalarında hem de hava sahası kapasitesinin verimli kullanılarak daha fazla sayıda uçuşun gerçekleştirilmesine imkân sağlayacaktır. Gelecek çalışmalarda bu modelin daha farklı hava sahalarında test edilmesi ve gerçek zamanlı benzetim çalışmaları ile kıyaslanması planlanmaktadır. 


\section{Referanslar}

Alonso-Ayuso, A., Escudero, L. F., \& Martín-Campo, F. J. (2012). A mixed 0-1 nonlinear optimization model and algorithmic approach for the collision avoidance in ATM: Velocity changes through a time horizon. Computers \& Operations Research, 39(12), 3136-3146.

Alonso-Ayuso, A., Escudero, L. F., \& Martín-Campo, F. J. (2016). Exact and approximate solving of the aircraft collision resolution problem via turn changes. Transportation Science, 50(1), 263-274.

Alonso-Ayuso, A., Escudero, L. F., \& Martín-Campo, F. J. (2016). An exact multi-objective mixed integer nonlinear optimization approach for aircraft conflict resolution. Top, 24(2), 381-408.

Cafieri, S., \& Durand, N. (2014). Aircraft deconfliction with speed regulation: new models from mixed-integer optimization. Journal of Global Optimization, 58(4), 613-629.

Cafieri, S., \& Omheni, R. (2017). Mixed-integer nonlinear programming for aircraft conflict avoidance by sequentially applying velocity and heading angle changes. European journal of operational research, 260(1), 283-290.

Cafieri, S., \& Rey, D. (2017). Maximizing the number of conflict-free aircraft using mixed-integer nonlinear programming. Computers \& Operations Research, 80, 147-158.

Cai, J., \& Zhang, N. (2019). Mixed Integer Nonlinear Programming for Aircraft Conflict Avoidance by Applying Velocity and Altitude Changes. Arabian Journal for Science and Engineering, 44(10), 8893-8903.

Campo FJ. (2010). The collision avoidance problem: methods and algorithms. PhD Thesis, Universidad Rey Juan Carlos, Madrid, Spain

Carlier, J., Nace, D., Duong, V., \& Nguyen, H. H. (2003). Using disjunctive scheduling for a new sequencing method in multipleconflicts solving. In Proceedings of the 2003 IEEE International Conference on Intelligent Transportation Systems, Vol (1), $708-714$.

Cecen, R. K., \& Cetek, C. (2019). A Two-Step Approach for Airborne Delay Minimization Using Pretactical Conflict Resolution in Free-Route Airspace. Journal of Advanced Transportation, 2019.

Cecen, R. K., \& Cetek, C. (2020). Conflict-free en-route operations with horizontal resolution manoeuvers using a heuristic algorithm. The Aeronautical Journal, 124(1275), 767-785.

Cecen, R. K., Saraç, T., \& Cetek, C. (2020). Meta-heuristic algorithm for aircraft pre-tactical conflict resolution with altitude and heading angle change maneuvers. TOP, 1-19.

Center, E. E. (2013). User manual for the base of aircraft data (BADA) revison 3.11. Brussels: Eurocontrol.

Christodoulou, M., \& Costoulakis, C. (2004). Nonlinear mixed integer programming for aircraft collision avoidance in free flight. In Proceedings of the 12th IEEE Mediterranean Electrotechnical Conference, Vol (1), 327-330

Hong, Y., Choi, B., Oh, G., Lee, K., \& Kim, Y. (2017). Nonlinear conflict resolution and flow management using particle swarm optimization. IEEE Transactions on Intelligent Transportation Systems, 18(12), 3378-3387.

ICAO. Rules of the Air and Air Traffic Services, Air Traffic Management. 15th ed. (2007) Montreal, Canada: International Civil Aviation Organization Publications.

Kuchar, J. K., \& Yang, L. C. (2000). A review of conflict detection and resolution modelling methods. IEEE Transactions on intelligent transportation systems, 1(4), 179-189.

Pallottino, L., Feron, E. M., \& Bicchi, A. (2002). Conflict resolution problems for air traffic management systems solved with mixed integer programming. IEEE transactions on intelligent transportation systems, 3(1), 3-11.

Richards, A., \& How, J. P. (2002). Aircraft trajectory planning with collision avoidance using mixed integer linear programming. In Proceedings of the 2002 American Control Conference, (3), 1936-1941.

Vela, A., Solak, S., Singhose, W. \&Clarke, J.P. (2009). A mixed integer program for flight-level assignment and speed control for conflict resolution, In Proceedings of the 48th IEEE Conference on Decision and Control, 5219-5226 